Mens

revue d'histoire intellectuelle de l'Amérique française

\title{
L'ironie contre la sagesse de la petite servante thrace : analyse d'un débat entre Jean Larose et Jacques Pelletier
}

\section{Jonathan Livernois}

Volume 9, numéro 1, automne 2008

URI : https://id.erudit.org/iderudit/1022819ar

DOI : https://doi.org/10.7202/1022819ar

Aller au sommaire du numéro

Éditeur(s)

Centre de recherche en civilisation canadienne-française

ISSN

1492-8647 (imprimé)

1927-9299 (numérique)

Découvrir la revue

Citer cet article

Livernois, J. (2008). L'ironie contre la sagesse de la petite servante thrace : analyse d'un débat entre Jean Larose et Jacques Pelletier. Mens, 9(1), 7-34. https://doi.org/10.7202/1022819ar
Résumé de l'article

La polémique qui opposa Jacques Pelletier (Les habits neufs de la droite culturelle) et Jean Larose (La souveraineté rampante) en 1994 révèle un " dialogue de sourds » (Marc Angenot) sur la définition et le rôle de la culture. Elle départage deux visions du monde : l'une, à laquelle se rattache Jean Larose, est romanesque et ironique, tandis que la seconde, qui subsume les idées de Jacques Pelletier, est rivée au concret, se veut sérieuse. La vision romanesque de la culture et du monde permet aussi de mieux comprendre la pensée d'une importante famille intellectuelle québécoise, groupée autour de la revue Liberté (surtout au cours des années 1980) et des Éditions du Boréal (surtout de la collection « Papiers collés »). 


\title{
L'IRONIE CONTRE LA SAGESSE DE LA PETITE SERVANTE THRACE : ANALYSE D'UN DÉBAT ENTRE JEAN LAROSE ET JACQUES PELLETIER ${ }^{1}$
}

\author{
Jonathan Livernois \\ Département de langue et littérature françaises \\ Université McGill
}

\section{Résumé}

La polémique qui opposa Jacques Pelletier (Les habits neufs de la droite culturelle) et Jean Larose (La souveraineté rampante) en 1994 révèle un " dialogue de sourds » (Marc Angenot) sur la définition et le rôle de la culture. Elle départage deux visions du monde : l'une, à laquelle se rattache Jean Larose, est romanesque et ironique, tandis que la seconde, qui subsume les idées de Jacques Pelletier, est rivée au concret, se veut sérieuse. La vision romanesque de la culture et du monde permet aussi de mieux comprendre la pensée d'une importante famille intellectuelle québécoise, groupée autour de la revue Liberté (surtout au cours des années 1980) et des Éditions du Boréal (surtout de la collection " Papiers collés »).

\section{Abstract}

The 1994 polemic opposing Jacques Pelletier (Les habits neufs de la droite culturelle) and Jean Larose (La souveraineté rampante) revealed, according to Marc Angenot, a "dialogue de sourds" on the definition and the role of culture. It highlighted two worldviews: the first, embraced by Jean Larose, was 
sentimental and ironic, while the second, which subsumed the ideas of Jean Pelletier, was concrete and presented itself as serious. The sentimental vision of culture and the world allows moreover for a greater understanding of the important Quebec intellectual current centred around the review Liberte (especially in the 1980s) and the Éditions du Boréal (especially in the "Papers collés" series).

À en croire Jacques Pelletier, professeur de littérature à l'UQÀM, une "nouvelle droite culturelle » domine le Québec en 1994. Ses représentants sont des écrivains et des critiques comme Jacques Godbout, Denise Bombardier, François Ricard et Jean Larose. Ils ont gravité un moment autour de la revue Liberté (surtout dans les années 1980, alors que François Ricard en était le directeur) et sont aujourd'hui, pour la plupart, aux Éditions du Boréal, dont la collection d'essais "Papiers collés » est aussi dirigée par François Ricard. Désabusés ou « débarrassés » de la question nationale depuis l'échec référendaire de 1980, ils sont résolument conservateurs : « La solution qu'il[s] entrevoi[ent] aux problèmes actuels du Québec, et qu'il[s] propose[nt] sous un emballage masqué par les enjolivures, n'est rien d'autre qu'un retour au modèle culturel dominant de cette société avant la Révolution tranquille ${ }^{2}$." Le titre du pamphlet de Pelletier, Les habits neufs de la droite culturelle. Les conservateurs et la nostalgie de la culture d'ancien régime, ne saurait être plus éloquent.

La table est donc mise pour une polémique importante. Pourtant, si la violence de l'attaque est évidente (Stéphane Baillargeon, dans Le Devoir, parlera des «couteaux et pamphlets [qui] volent bas $\left.^{3} »\right)$, il y a peu de réponses de la part des intellectuels attaqués. Pelletier le dit lui-même, peu de temps après la parution de son pamphlet: "Le débat sur l'avenir de la culture et de l'école québécoises, amorcé dans mon petit livre, n'a pas été suivi d'échanges polémiques, sur des tribunes publiques, avec les écrivains et les intellectuels concer- 
nés ${ }^{+}$. " En effet, Godbout évoque bien le "procès idéologique » de Pelletier dans l'avant-propos de la réédition du Réformiste, traite de la culture «sirop d'érable » dans un entretien avec Gilles Marcotte ${ }^{5}$, mais sans plus. Pour Ricard, «il faut vivre et laisser braire »; les dichotomies gauche/droite ne sont, au mieux, que de "l'étiquetage caricatural» auquel il n'accorde « aucune importance ${ }^{6} »$. On notera cependant son texte "Le grand humour», paru en mai 2001 dans l'Inconvénient, où il s'attaquera à son tour, avec une ironie décapante, aux idées de Pelletier?. Les choses deviennent plus intéressantes dans le cas de Jean Larose, qui consacre un long chapitre de $\mathrm{La}$ souveraineté rampante (1994) aux arguments de Pelletier. Cependant, ce dernier ne répliquera pas, ne sachant trop sur «quelles bases [il pourrait] décemment poursuivre la discussion et proposer une contre-argumentation à un discours constitué pour l'essentiel d'insultes, d'injures et dépourvu, pour reprendre une expression de Pierre Milot, de toute rationalité argumentative ${ }^{9}$ ». Le dialogue de sourds, pour parler comme Marc Angenot, persiste. Comment expliquer cette incapacité de dialoguer? La gauche et la droite sont-elles en cause ?

C'est du moins le jeu de Jacques Pelletier : il est à gauche et ses ennemis sont nécessairement à droite. Et il n'est pas seul de son côté : Pelletier s'inscrit dans une longue tradition qu'Yvan Lamonde nomme, dans son arborescence des principaux courants de pensée au Québec de 1760 à nos jours, "pensée et pratique de gauches contemporaines ", sillage dans lequel on retrouve Pierre Maheu, Jean-Marc Piotte, Pierre Vallières et Gilles Bourque, mais aussi Pierre Gélinas et Jacques Perrault ${ }^{10}$. Même s'il n'a pas participé directement à l'aventure de Parti pris, revue socialiste et séparatiste, il dit avoir vécu cette "aventure intellectuelle $[. .$.$] à un haut ni-$ veau d'intensité » et que «rien depuis ne [lui a] procuré une sensation du même ordre ${ }^{11}$ ». Cette gauche à laquelle il adhère 
est résolument nationaliste. C'est donc fort de ce double ancrage, souverainiste et de gauche, qu'il dénoncera - nous le verrons - «l'universalisme abstrait» de la "nouvelle droite culturelle », représentée entre autres par Jean Larose. Cette prise de position peut étonner : historiquement, ce sont surtout des tenants de la droite qui dénoncèrent l'internationalisme des gens de gauche ${ }^{12}$. Les catégories sont-elles brouillées? En tout cas, pour François Ricard, ces positions idéologiques ne valent plus grand-chose : "J'aurais le goût de lui [Pelletier] demander à droite de quelle gauche je me situe. [...] Ces catégories sont de moins en moins prégnantes dans le contexte actuel [...]. Par exemple, les syndicats qui refusent le partage du temps de travail sont-ils de droite ou de gauche ${ }^{13}$ ? " Jean Larose, dans La souveraineté rampante, s'interroge aussi :

Comme tout le monde, je me suis demandé depuis quelle " gauche " Jacques Pelletier nous lançait, à Bombardier, Godbout, Ricard et moi-même - et au "réseau » puissant et vaguement occulte auquel nous appartiendrions -, cette accusation, qui se réfère à un antagonisme de moins en moins clair dans la vie politique de notre époque, d'être de «droite ». (SR, p. 43)

Ricard et Larose semblent s'entendre sur le fait que ces positions sont tout sauf sûres, claires. S'ensuivront dans leurs écrits une sorte de flou et un refus de se cantonner dans l'une ou l'autre de ces catégories. Ils préféreront réclamer, même lorsqu'ils s'intéresseront à des questions sociales qui pourraient nécessiter une prise de position nette, la souveraineté littéraire et l'ironie. Ils n'évacuent pas pour autant la gauche et la droite : celles-ci deviennent des matériaux littéraires qu'ils croient infléchir et travestir à satiété. En somme, ce n'est pas tant l'opposition entre la gauche et la droite qui crée le dialogue de sourds que la façon d'inscrire et d'infléchir ces positions dans les textes; façon qui découle, pour Jean Larose, 
d'une conception du monde et de la culture opposée à celle de Jacques Pelletier. Dans leurs philippiques respectives, Larose reprend ces catégories et s'en sert comme des ressorts littéraires bien bandés, tandis que Pelletier se pose en homme de gauche grave qui refuse qu'on puisse badiner avec ces choix idéologiques. Voilà deux positions irréconciliables.

Je propose, dans ces pages, une analyse rhétorique des pamphlets de Pelletier et de Larose qui révélera cette faille et permettra de mieux la définir : chez Pelletier, on notera un ton « réaliste ", sérieux, objectif, solidement enraciné dans le vécu et dans le concret; chez Larose, il s'agira plutôt d'un ton ironique et non sérieux, du badinage, de la «souveraineté littéraire ». Par la polarisation de ces jeux littéraires, apparầtra cette incompatibilité profonde des conceptions du monde et de la culture. Comme l'a bien vu Marc Angenot, de tels «blocages conceptuels » empêchent plus souvent qu'autrement le débat ${ }^{14}$.

\section{La sagesse de la petite servante thrace}

Il n'est pas inutile de rappeler que l'idée de culture soustend au moins deux acceptions différentes, bien décrites par Alain Finkielkraut dans La défaite de la pensée. Il y a d'abord la culture comme «domaine où se déroule l'activité spirituelle et créatrice de l'homme "; il y a ensuite la culture comme « esprit du peuple auquel j’appartiens et qui imprègne à la fois ma pensée et les gestes les plus simples de mon existence quotidienne ${ }^{15}$ ». La première constitue en quelque sorte l'héritage des chefs-d'œuvre universels (la "culture savante") tandis que la seconde se décline comme une culture particulière (la "culture populaire ") décrite aussi par Fernand Dumont comme "l'outillage dont disposent les individus d'une société donnée (un langage qui définit partiellement des concepts, des coutumes, des traditions, etc. $)^{16} »$. 
L'importance accordée à l'une ou à l'autre des définitions de la culture est au cœur d'un vieux débat culturel québécois. Jacques Godbout rappelle :
À l'époque de Claude-Henri Grignon, de Valdombre qui était son nom de plume, il y avait une discussion à n'en plus finir entre les régionalistes auxquels il appar- tenait bien sûr et les internationalistes auxquels proba- blement des gens comme Alain Grandbois devaient s'associer, qui lui voyageait en Chine et sur les traces de Marco Polo. C'est évident qu'entre celui qui écrit $U n$ bomme et son péché et qui décrit Séraphin Poudrier et celui qui s'en va chercher une réponse à ses angoisses en Chine, on a affaire à deux personnes et c'est probable- ment que ces deux grands courants-là sont fondamen- taux dans une société comme la nôtre ${ }^{17}[. .$.

Variation, donc, sur le thème du régionalisme et de l'exotisme ${ }^{18}$, du particulier et de l'universel depuis au moins les années $1930^{19}$. Félix-Antoine Savard résume bien le débat au milieu des années 1950 :

Il en est qui refusent le temps (le tempus acceptabile, dont parle l'Écriture), pour s'évader vers des absolus artificiels. Ils ont l'esprit et le cœur en révolte contre les conditions de lieux et de temps où Dieu nous a placés ; ils s'égarent en des métaphysiques fumeuses, en des universalismes - assez confortables, d'ailleurs - où la pensée, séparée du concret et de l'immédiat, n'a plus d'autres règles que son propre plaisiri ${ }^{20}$.

Jean Larose, qui ne fait que rebattre les cartes, lui répond indirectement quarante ans plus tard : « Où est "ici" pour l'écrivain? Il y a des jours où la Rome d'Héliogabale est plus proche de son vécu que les passants qui se promènent sous sa fenêtre. Mais allez donc expliquer ça à un nationaliste. Ressentiment contre force. Crainte boudeuse de la souveraineté intellectuelle. » (SR, p. 61) Pour Larose, la Rome d'Hélioga- 
bale est le gage - excessif, délibérément hyperbolique - de la liberté de l'écrivain, qui ne doit pas être prisonnier d'un quelconque nationalisme, surtout si celui-ci est refermé sur luimême. Larose pense sans doute au nationalisme castrateur propre à la "petite noirceur» des années postréférendaires :

$\mathrm{Il}$ en résulte tout simplement un retour au bon vieux nationalisme canadien-français. À cette différence près que le Baptiste, dans sa statue en papier "de dix pieds de hauteur" à l'Oratoire, n'est plus représenté enfant, mais adulte : c'est pire, cela signifie peut-être que la "grande noirceur" a passé avec succès l'épreuve de sa modernisation. Appelons cela la petite noirceur".

Dans de telles circonstances, le constat de Pierre Vadeboncoeur, au début des années 1960, est toujours d'actualité : «Cette préoccupation collective est nettement obsessionnelle. Je ne crois pas qu'un seul écrivain s'en soit vraiment dégagé, sauf s'il s'est plus ou moins expatriééc. » Jacques Godbout ne dira pas autre chose : " Je crois à l'indépendance de l'écrivain, à la nécessité qu'a l'écrivain de prendre ses distances avec son milieu, parce qu'autrement il va tout simplement chanter la gloire du milieu. Est-ce qu'on est là pour $\mathrm{ça}^{23}$ ? » En somme, la culture, «le domaine où se déroule l'activité spirituelle et créatrice de l'homme », pour reprendre Finkielkraut, n'est pas inféodée à un quelconque service national obligatoire. Au contraire, la culture profitera de la souveraineté littéraire, des rapports féconds, vécus par les écrivains, entre l'enracinement et le déracinement ${ }^{24}$.

Jacques Pelletier envisage les choses un peu différemment : il faut ancrer la culture savante dans la culture populaire. C'est la position qu'il défendra dans Les babits neufs de la droite culturelle contre celle des "laroso-ricardiste ${ }^{25}$ »:

[La solution des tenants de la nouvelle droite culturelle] implique en outre le refus de la culture populaire 
considérée en bloc comme une expression dégradée de l'art et de la littérature et la célébration sans réserve d'une culture savante, entièrement coupée de la culture populaire, faite par et pour des cercles restreints de pairs, d'initiés et de spécialistes pratiquant ce que Jean Duvignaud appelle un art des réserves et des huis clos inaccessible aux "non-instruits", comme disait suavement Jean Lesage naguère ${ }^{26}$.

Et que propose Pelletier ? Une sorte de solution dumontienne : la transmission de la culture québécoise, sur laquelle nous avons "une prise réelle », en accordant, "dans les pratiques culturelles, dans l'enseignement et plus globalement dans notre société, la tradition dans ce qu'elle a de plus vivant (y compris les "classiques" contextualisés) et la modernité la plus contemporaine dans le cadre d'un projet visant à créer une société plus juste ${ }^{27}$ » et plus solidaire. Autrement dit, il faut s'astreindre à " aménager des ponts entre cette culture et la culture savante, à tenter de réduire la distance exponentielle qui les sépare de plus en plus, à faciliter les échanges et les passages de l'une à l'autre », et ainsi, faire en sorte " qu'il puisse se produire un enrichissement réciproque, plus souhaitable que l'actuelle séparation et le mépris de part et d'autre qui lui est lié $^{28} »$. L'objectif ultime est donc la construction d'« une véritable culture nationale, comprenant un certain nombre de valeurs majoritairement sinon unanimement partagées et une langue commune de communication et d'échange " ( $H N, \mathrm{p}$. 16).

Si Larose rappelle que, parfois, l'écrivain québécois est plus proche de la Rome d'Héliogabale que des passants sous sa fenêtre, il ne nie pas pour autant que la culture comme " esprit du peuple », si méprisable soit-elle à l'occasion, puisse aussi servir la culture universelle, dans la mesure où celle-là n'empêche pas celle-ci. Ce rapport que Larose entretient avec le Québec est typique de l'esprit de la «famille » intellectuelle 
groupée autour de Liberté et des Éditions du Boréal. François Dumont l'a bien vu dans une pertinente analyse consacrée à la collection "Papiers collés »: si le Québec est intériorisé, s'il devient une sorte de tremplin vers une pensée universelle, «il permet de véritables ouvertures, sans qu'aussitôt, pour reprendre cette fois-ci les termes d'André Belleau, "l'univers se rapetisse" et se replie dans le "village primordial" "29" ". Faisant fi du paradoxe que constitue ainsi «l'indépendantisme antinationaliste ${ }^{30}$ » d'un Jean Larose, tourné vers une conception bataillienne de la souveraineté littéraire et politique, Jacques Pelletier cherche plutôt à réduire la position de son adversaire à une sorte d'universalisme désincarné, coupé de la culture populaire. Pour ce faire, il reprend justement l'esprit du peuple, les paroles de la sagesse populaire : qui monte trop haut finit par se perdre; il faut savoir garder les pieds sur terre. On pourrait décrire cette sagesse "populaire " (qui ancre la culture savante, dirait Pelletier) comme celle de la petite servante thrace, pour rappeler le personnage du Théétète de Platon :

Thalès étant, mon cher Théodore, tombé dans un puits, tandis que, occupé d'astronomie, il regardait en l'air, une petite servante thrace, toute mignonne et pleine de - bonne humeur, se mit, dit-on, à le railler de mettre tant d'ardeur à savoir ce qui est au ciel, alors qu'il ne s'apercevait pas de ce qu'il y avait devant lui et à ses pieds ${ }^{31}$ !

Depuis que le premier ministre Duplessis a raillé les « pelleteux de nuages ${ }^{32}$ » qu'étaient pour lui les intellectuels, plusieurs ont rebattu et rebattent encore, au Québec, des expressions dérivées de cette sagesse de la petite servante thrace. Plus encore, cette sagesse est au cœur d'une longue tradition occidentale, des Nuées d'Aristophane à Michelet :

En nationalité, c'est tout comme en géologie, la chaleur est en bas. Descendez, vous trouverez qu'elle aug- 
mente ; aux couches inférieures, elle brûle. [...] Quel froid, si je monte plus haut ! c'est comme dans les Alpes. J'atteins la région des neiges. La végétation morale disparaît peu à peu, la fleur de la nationalité pâlit. [...] Que je monte encore d'un degré, la peur même a cessé, c'est l'égoïsme pur du calculateur sans patrie ; plus d'hommes, mais des chiffres... Vrai glacier abandonné de la nature... Qu'on me permette de descendre, le froid est trop grand ici pour moi, je ne respire plus ${ }^{33}$.

Il faudrait aussi citer Nietzsche : "La vie devient de plus en plus rude à l'approche des sommets - le froid augmente, la responsabilité augmente. Une culture élevée est une pyramide : elle ne peut reposer que sur une base, elle a pour condition première une médiocrité fortement et sainement consolidée ${ }^{34}$. " Tous ces passages insistent sur la dichotomie sol fertile/sommet aride où l'air se raréfie, joue avec la polysémie du substantif «culture » et avec l'origine romaine de ce mot, expliquée par Hannah Arendt dans La crise de la culture ${ }^{35}$. Julien Benda, dans La Trabison des clercs, écrit à propos des "clercs modernes » :

Les clercs modernes font mieux : ils déclarent que leur pensée ne saurait être bonne, donner de bons fruits, que s'ils ne quittent point leur sol natal, s'ils ne se "déracinent" pas. [...] L'esprit déclaré bon dans la mesure où il refuse de se libérer de la terre, voilà qui assure aux clercs modernes une place de marque dans les annales du spirituel. Les sentiments de cette classe ont évidemment changé depuis que Plutarque enseignait: “L'homme n'est pas une plante, faite pour demeurer immobile et qui ait ses racines fixées au sol où il est né", ou qu'Antisthène répondait à ses confrères, glorieux d'être autochtones, qu'ils partageaient cet honneur avec les limaçons et les sauterelles ${ }^{36}$. 
Jacques Pelletier loge à l'enseigne de ces clercs modernes. Pour reprendre cette sagesse de la petite servante thrace, non seulement il présentera une série d'images de verticalité qui opposent les hauteurs métaphysiques arides et le sol fertile de la culture populaire, mais il donnera aussi un tour sérieux à ses démonstrations, dont l'objectivité devra être patente.

\section{L'irrationalité de Jean Larose}

[...] c'est à cette prétention de savants, d'hommes qui combattent pour une vérité trouvée dans la sévérité du laboratoire, c'est à cette posture de clercs guerroyants, mais de clercs, qu'ils doivent l'audience spéciale dont ils bénéficient entre les hommes d'action ${ }^{37}[. .$.

Julien Benda, La trabison des clercs, 1927.

Dès les premières lignes de ses Habits neufs de la droite culturelle, Pelletier réclame un débat qui se déroulera sur la place publique de la République des Lettres : «Indépendamment de ces perceptions et appréciations personnelles, assez variables, ces écrivains et critiques ont en commun d'être pour moi des adversaires sur les plans intellectuel, idéologique et politique. C'est sur ce terrain-là, d'ailleurs, que je prétends les confronter et les discuter. " (HN, p. 21) Cette revendication d'une "éthique de la discussion" appelle un climat d'objectivité que Pelletier recherche en enchaînant les faits qui viendront, croit-il, confirmer sa thèse et détruire les idées sans fondement de Larose. Le procédé est simple : Pelletier affirme $x$, extrait des passages des textes de Larose qu'il juge révélateurs et croit ainsi prouver ses dires. Il n'hésite pas non plus à présenter les analyses de Larose (sur la défaite référendaire, sur la modernité littéraire québécoise et sur la France) comme des états d'âme sans fondement, voire "délirants» (HN, p. 38). Il confronte les dires de l'adversaire à ce qu'il considère 
être des faits socio-historiques pour mettre en lumière sa propre objectivité et l'invalidité des idées de Larose.

La thèse de Pelletier est simple : la position de Larose est irrationnelle et constitue un exemple parfait d'une culture anachronique, universaliste, savante et élitiste, coupée de la fertilité de la culture populaire. Il faudra en convaincre un destinataire que Pelletier inscrit dans le texte par le pronom " on ». Un pronom qui n'est pas sans marquer une certaine pluralité, un peu comme si Pelletier ne s'excluait pas du groupe auquel il s'adresse. Mais l'absence du « je » et la présence du «on » marquent aussi une sorte de position objective, mise en relief de l'irrationalité de Larose qui, lui, écrit à la première personne.

Le décor est planté dès les premières phrases du chapitre des Habits neufs consacré à Larose :

Est-il possible de rendre compte objectivement des analyses et des propositions avancées par Jean Larose dans L'amour du pauvre, de les considérer pour ellesmêmes, en faisant abstraction de la manière particulièrement désagréable dont elles sont énoncées?

Ne risquerait-on pas alors de passer à côté de l'essentiel, c'est-à-dire de l'attitude, de la posture, hautaine, dédaigneuse, de l'analyste à l'endroit des réalités « dégradées » dont il parle ? Ces pauvres réalités qui constituent la littérature québécoise, la culture populaire, le féminisme, le mouvement gai, la création littéraire, le nationalisme québécois, Larose les passe en revue et les exécute d'un revers de la main, sans prendre la peine de les analyser, se contentant de les juger et de les rejeter du haut de la tour à laquelle il s'agrippe et d'où il plonge un regard averti et blasé sur le petit monde mesquin, sans grandeur - et en cela québécois, bien sûr ! - qui l'entoure. (HN, p. 23) 
Par ces questions oratoires, Pelletier annonce clairement son programme, et s'excuse presque de devoir stigmatiser l'essayiste Larose, tant ses idées sont présentées avec mépris. Autrement dit : il utilisera une série d'arguments ad personam dans ce texte, mais cette "dégradation» de l'éthique de la discussion est nécessaire si l'on veut comprendre l'irrationalité de celui qui juge du « haut de sa tour ». Déjà, l'isotopie de la «verticalité » est présente. N'en rappelons que quelques traces : la posture de Larose est « hautaine», il juge du « haut de sa tour» (HN, p. 23) ; il est «là-haut sur la montagne» ( $H N$, p. 24), enseignant à « l'université de la montagne» ( $H N$, p. 36), " en retrait, en surplomb ", « respirant un air parisien " (HN, p. 24). Sans compter qu'il ne juge pas le Québec à sa « hauteur » (HN, p. 32), mais condamne sa culture de masse à partir de "principes abstraits» (HN, p. 26). Pour Pelletier, ces jugements du "haut de la montagne » sont irrationnels, voire assimilables à des comportements psychiatriques que le clinicien sait relever. Ainsi, le rapport de Larose à la culture française est un « rapport névrotique » $(H N$, p. 33$)$ qui relève d'une "projection fantasmatique » ( $H N$, p. 32) et d'une "dénégation furieuse de la société à laquelle il appartient» ( $H N$, p. 37). Ce vocabulaire psychanalytique qui apparaît çà et là dans l'argumentation de Pelletier et qui lui confère une certaine «scientificité » est aussi appuyé par le vocabulaire sociologique bourdieusien, qui a d'ailleurs un effet-repoussoir sur la pensée de Larose ${ }^{38}$. On peut ainsi parler d'une sorte de transfert d'autorité qui permet de passer des conclusions de Bourdieu sur le champ littéraire à celles de Pelletier. Si cette récupération est encore plus évidente dans un texte comme "Le débat impossible $e^{39}$ ?", dans lequel Pelletier cherche à saisir les réactions aux thèses de son essai en appliquant les concepts du sociologue français, le professeur de l'UQÀM n'hésite pas non plus, dans Les babits neufs de la droite culturelle, 
à référer au « champ littéraire québécois » (HN, p. 30), à l'autonomie du champ culturel dans les sociétés modernes, mais aussi au "bourdieusien » Pierre Milot, qui aurait mis en évidence, chez l'auteur de L'amour du pauvre, "la fragilité d'une "méthode" reposant plus sur l'intuition inspirée (par Dieu ?) que sur l'étude objective des phénomènes considérés " (HN, p. 32). L'allusion à Dieu n'est pas innocente : elle place les «méthodes » de Larose du côté de l'irrationnel, du sentiment religieux, les écartant de la rationalité moderne revendiquée par Pelletier. Il y a aussi une isotopie du sacré dans le texte de Pelletier, qui confère à la pensée de Larose un caractère anachronique, d'avant la Révolution, qu'elle soit française ou tranquille. Ainsi, les solutions de Larose seraient présentées sous forme d'« encycliques papales ». (HN, p. 25), prôneraient la "sainte souffrance de l'effort", une "sanctification de la culture savante » et une conception de la littérature comme " une série de grands textes exemplaires devant lesquels on s'incline, on se prosterne et on se signe en tremblant sur le mode (et à l'exemple) de la dévotion religieuse » (HN, p. 39). Ce sont là autant de signes qui portent à croire que Pelletier cherche à assimiler les positions de Larose à des comportements d'« ancien régime » (c'est le sous-titre de son pamphlet), argument de comparaison qui place implicitement Larose $\mathrm{du}$ côté des ennemis de la Révolution française, qu'il s'agisse des éléments les plus réactionnaires du clergé ou d'une aristocratie (c'est la posture de Larose) composée des pires roués. En fait, pour Pelletier, homme de gauche, le processus de cette Révolution n'est pas complété : "les opposants [de la nouvelle droite culturelle], ce sont les "modernes", les partisans des Lumières, ceux qui estiment que l'Histoire n'est pas terminée, que le progrès est toujours possible et souhaitable, ceux pour qui, enfin, le programme à trois volets de la Révolution française et des démocraties qui s'y sont reconnues par la suite 
demeure à réaliser. " $(H N, 17)$ Pelletier récupère cet héritage de la liberté, de l'égalité et de la fraternité contre l' " aristocratie » nietzschéenne de Larose, son dédain ironique, son irrationalité d'inspiration divine. Pelletier ne croit pas qu'on puisse badiner avec la vérité.

Pourtant, les faits de Pelletier relèvent souvent du vraisemblable, voire du lieu commun. Pierre Milot, qui n'est pourtant pas le pire des adversaires de Pelletier, le dit bien : « Pelletier s'avance, visière baissée, avec une méconnaissance certaine des recherches les plus récentes de l'histoire sociale et intellectuelle, et de la sociologie de la littérature concernant le passage de la Grande Noirceur à la Révolution tranquille ${ }^{40}$. » Et les citations sur lesquelles repose l'édifice logique de Pelletier ne sont généralement que des extraits des textes de Larose, souvent réduits à un mot. Mais à l'en croire, ce sont de véritables pièces à conviction : "c'est écrit en français dans le texte ; qui dit mieux?» (HN, p. 27) Larose refuserait et dénigrerait ainsi « la littérature québécoise, la culture populaire, le féminisme, le mouvement gai, la création littéraire, le nationalisme québécois » (HN, p. 23). C'est le refus généralisé, le mépris complet, d'ailleurs marqué par une anaphore (" refus ", voir $H N$, p. 39) à la toute fin du texte. Une lecture des essais de Larose permet cependant de voir que ces citations sont souvent " travesties » et qu'elles mènent parfois à des sophismes d'inférence, qui consistent à faire dire à la citation bien plus que ce qu'elle révèle. Ainsi Larose entretiendrait des "préjugés grossiers [...] sur les gais et le Québec » (HN, p. 26). Pelletier cite l'auteur de L'amour du pauvre: «le Québec [...] serait alors, à l'en croire, une "sorte de pays gai" (p. 227)» (HN, p. 26). Un retour à cette page de L'amour du pauvre suffit pour montrer l'aspect fallacieux d'un tel raisonnement : Pelletier invoque des mots qui ne sont pas de Larose, mais d'un personnage, fort ridicule par ailleurs ${ }^{41}$. 
Un autre exemple, à propos du cours classique. Pelletier invoque souvent cette preuve : "l'ancien cours classique véhiculait, semble-t-il, une "tradition de critique et d'innovation" (p. 42) [...] " (HN, p. 24) Cette citation de six mots fait boule de neige : Larose ne valorise que la culture classique et refuse la littérature québécoise qui est celle du pauvre. Il refuse aussi le nationalisme québécois comme une manifestation primitive (Pelletier l'associe au " fédéraliste intransigeant et notoire» (HN, p. 39) Jean Le Moyne et, par ricochet, à Pierre Trudeau et à Mordecai Richler). Il abhorre aussi tout ce qui relève de la culture populaire et qui n'est pas une « idéalisation » de la «culture savante, élitiste» (HN, p. 39). Le « retour en arrière » se traduit finalement par une pédagogie " coercitive, disciplinaire, privilégiant la mémoire, le par cœur, la passivité » (HN, p. 41). Pourtant, Larose, lorsqu'il parle d'une "tradition de critique et d'innovation » dans L'amour du pauvre, traite de la culture humaniste et montre plutôt que celleci n'est pas exclusive au cours classique ${ }^{42}$. De même, il ne qualifie pas la littérature québécoise de «littérature du pauvre $»$, bien au contraire ${ }^{43}$. Il ne s'agit ici que de quelques sophismes d'inférence. L'argumentation, qui se voulait objective, est viciée.

Mais comment un universitaire, dont la fréquentation des textes littéraires est le métier, peut-il imputer à un auteur les réflexions et les paroles de ses personnages, comme c'est le cas ici ? La réponse réside peut-être dans la conclusion du texte de Pelletier, où celui-ci affirme que les essais de Larose " n'aident guère la discussion en raison d'abord de ce que l'auteur appelle sa "saine arrogance" et qui n'est rien d'autre qu'un mépris total pour la plus grande partie - sinon l'ensemble - de la culture qui se construit ici et pour ceux qui la font » (HN, p. 43-44). Cette «saine arrogance» dont parle Pelletier est sans aucun doute l'ironie de Larose. L'ironie est 
en effet une expression privilégiée de la culture défendue par les "laroso-ricardistes", souveraine et désenchantée, plus encline à «l'ironie du roman » qu'à «la croyance de la poé$\operatorname{sie}^{4+}$ ", à la littérature qu'aux théories comme méthode et comme art de vivre. De la même manière, François Ricard, l'un des maîtres de cette ironie, passé de Libertét5 à l'Inconvénient et à L'Atelier du roman, ne cherchera pas, lorsqu'il dessinera le portrait de sa génération lyrique, à multiplier les faits et les théories. Aucune objectivité n'est réclamée lorsqu'il écrit : «Ma méthode, en somme, si on me forçait à la définir, je dirais que c'est celle, tout simplement, de la littérature ${ }^{46}$. »

La littérature souveraine contre l'objectivité des faits, du concret, renforcée par la sagesse populaire de la petite servante thrace : autrement dit, une opposition entre un monde romanesque et un monde scientifique ${ }^{47}$, entre le non-sérieux et le sérieux. Plus qu'une simple dichotomie gauche/droite, ce que révèle l'analyse des procédés rhétoriques de Pelletier et de Larose, c'est une coupure profonde qui condamne à un dialogue de sourds, chacun des protagonistes vivant sur sa planète culturelle. Pis encore, la distance qui sépare leurs visions du monde et de la culture semble exacerbée par le ton et la forme de leurs écrits.

\section{Pour une littérature non sérieuse}

Aujourd'hui, je comprends - et cette découverte doit beaucoup aux événements que je vais raconter - qu'en répudiant mon ironie j'avais perdu l'esprit ${ }^{48}$.

$$
\text { Jean Larose, L'amour du paurre, } 1991 .
$$

François Ricard, dans sa réponse tardive à Pelletier paru dans l'Inconvénient, montre que l'absence d'ironie chez le professeur de l'UQÀM est une sorte de tare québécoise. Comme il l'a montré ailleurs, cette revendication du sérieux marque 
encore la critique : « Ne sommes-nous pas portés, aujourd'hui encore, à privilégier, dans le corpus québécois passé et présent, les écritures de combat ou d'enseignement, de témoignage ou de contestation ouverte, en somme les écritures utiles et conséquentes ${ }^{49}$ ? »Ce refus du badinage est présent chez Pelletier, qui use, à en croire Ricard, du "même ton assuré, [de] la même "conviction" profonde, [du] même sérieux implacable ${ }^{50}$ ». Celui-ci ne s'en cache d'ailleurs pas : "Je suis plutôt de ceux - dont se démarque Larose - qui tentent de développer un "énoncé sérieux soutenant sans broncher la ligne de son raisonnement" : cela me paraît plus sérieux que leur "méthode" faite d'approximations et d'à-peu-près ${ }^{51}$. "

Larose, dans sa réponse à Pelletier, sait que son adversaire ne partage pas le même terrain intellectuel. Plutôt que de tenter un rapprochement, il marque encore plus clairement la distance en exacerbant l'ironie : "Je ne me suis pas retenu en effet d'entrelarder certains passages de ce que mes censeurs comprennent le moins dans mes essais, des échappées d'éloquence, des exagérations véhémentes, quasi fictionnelles. " (SR, p. 24). Larose jouera ainsi à l'ironiste qui talonne l'adversaire et démasque son imposture en lui présentant " simplement un miroir pour qu'il rougisse de son visage mensonger ${ }^{52}$ ", comme l'écrivait Vladimir Jankélévitch à propos de l'ironie. Autrement dit, Larose s'amusera (la souveraineté littéraire est une question de $\mathrm{jeu}^{53}$ ) à reprendre les arguments de Pelletier contre ce dernier (phénomène de rétorsion), pour ensuite les hypertrophier afin de les ridiculiser et ce, jusqu'à ce qu'ils prennent une couleur ironique, non sérieuse, désamorçant le dogmatisme présumé de l'auteur des Habits neufs de la droite culturelle.

Dans le chapitre "Pelletier, Foglia et les pédagogues", Larose consacre plus de trente pages à saper les bases de l'argumentation de Pelletier. On trouve dans ce texte une 
grande richesse rhétorique : des arguments d'autorité (Nietzsche, Schlegel, Adorno, Proust, Benjamin, Kierkegaard), des hypotyposes délirantes (j'y reviendrai), des arguments $a d$ personam (par exemple, un rapprochement hyperbolique avec Slobodan Milosevic, voir SR, p. 48), des apostrophes et des marques orales (" Ah ! [soupir] Pelletier, si vous m'aviez lu... » [SR, p. 55]) qui renforcent, me semble-t-il, la position véritable de Larose : celle de l'orateur de l'agora, celle du rhéteur qui, devant le «danger qui menace la patrie » (SR, p. 42), accomplit son "devoir de citoyen" (SR, p. 42). Il avertit ses " concitoyens» ( $S R$, p. 43) en leur faisant part, "modestement » (SR, p. 43) prend-il soin de spécifier dans son « exorde", de ses réflexions. Les Perses ne s'approchent pas de l'Attique, mais le nationalisme du ressentiment (ou la petite noirceur) dont la prose de Pelletier est un exemple patent écrase la souveraineté québécoise, autant littéraire que politique. Il y a péril en la demeure.

Mais pourquoi Larose revendique-t-il cette position de Démosthène du cru ? Sans doute parce que cette position est résolument ironique : si Pelletier accuse Larose d'être passéiste, de s'élever dans une tour d'ivoire et d'être coupé de la culture populaire, il suffit, pour ce dernier, d'hypertrophier cette soi-disant "posture du mépris » en réclamant le rôle du maître rhéteur. Larose se met en scène comme s'il réfléchissait dans le calme de sa retraite tout en étant capable de s'emporter, parfois, dans de grands élans - «ce brin d'exagération qui suspend chez [lui] les sujets les plus sérieux » (SR, p. 41) sur l'agora. Larose s'amuse :

N'eût-il pas été criminel que, informé comme je l'étais d'une menace aussi certaine que cachée, je me tusse et, solitaire, avançant mes travaux de plume sans m'inquiéter des plus démunis auxquels la science de la littérature ne confère pas comme à moi une voyance spé- 
ciale sur les périls collectifs, je n'exploitasse pas l'occasion formidable, unique, prophétique, que me proposait le livre de Jacques Pelletier? (SR, p. 42)

L'emploi du subjonctif imparfait et cet élan ont bien quelque chose de délibérément précieux, vieillot, qui rappelle le collège classique, dont Pelletier accuse Larose d'être un admirateur nostalgique. Larose reprend sa posture du Magister : «Dans une fiction, même le narrateur est un personnage, faut-il le préciser? Voilà de ces banalités qu'on ne croyait plus devoir expliquer à un professeur de littérature à l'université. Luce clarius, praeter uquam. » (SR, p. 49) On aura saisi l'ironie de Larose : s'il veut rappeler à ses concitoyens que de tels truismes sont "clairs comme le jour, au-delà de l'UQÀM", il le fera en latin, gonflant à l'excès - jusqu'à ce que le sérieux soit désamorcé - sa pédanterie et ce soi-disant mépris des masses que lui reproche l'auteur des Habits neufs de la droite culturelle. L'ironie est aussi évidente dans cette hypotypose :

Oui, c'était à moi, je l'ai compris en juillet un soir de crépuscule, comme le soleil lavait dans le sang notre beau ciel laurentien, à moi de tirer cette larve au terme, de lui donner mon travail, par ma lucidité, par ma générosité, par mon amour enfin, ce qu'il lui manquait pour qu'elle atteignit l'imago, comme on dit pour les papillons. (SR, p. 42)

Dans ce morceau d'un style pompier, qui pastiche les plus mauvais vers de notre littérature nationale ("le soleil lavait dans le sang notre beau ciel laurentien $»)$, Larose semble presque parler depuis son refuge sur la montagne - « dont le relief affole tellement [la] jalousie » (SR, 55) de Pelletier. Il choisit de descendre et de rejoindre les gens sur la place publique, comme Zarathoustra. Mais s'il descend, c'est pour mieux remonter. Le renversement des arguments de Pelletier, c'est aussi le renversement de la sagesse de la petite servante thrace : 
«Tous ceux qui prendront votre défense le feront nécessairement depuis les mêmes ténèbres, pressés bientôt de vous fuir, et de remonter à la lumière. » (SR, p. 56, je souligne) Larose reprend le thème philosophique de la montée vers la Vérité, celui du détachement platonicien des " ténèbres environnantes » vers l'eidos, relayé dans le christianisme par la lumière divine. Si Dieu est mort (Nietzsche est partout chez Larose), la lumière n'est plus à chercher ailleurs que dans sa propre et vertigineuse souveraineté. Si Pelletier attaque Larose en multipliant les références à l'Église catholique, ce dernier ne semble nullement embarrassé, gonflant l'attaque jusqu'à se faire clerc: «Pour vous, pour vous seul nulle consolation, nulle remise de peine, l'enfer!» (SR, p. 56) Le clerc Larose n'hésite pas à excommunier, non plus.

Mais l'argumentation de Larose finit par tourner à vide. Stigmatiser Pelletier en le rabaissant au niveau d'un Homais de la littérature a pour conséquence de figer le mouvement du non-sérieux. L'hyperbole finit par ne plus mettre en relief l'inanité présumée d'une notion comme la droite culturelle: elle relance et exacerbe au contraire la dichotomie gauche/ droite que Larose cherchait à railler. Ce dernier associe ainsi le nationalisme et la gauche de Pelletier au "national-communisme » (SR, p. 48) de Slobodan Milosevic. La charge est d'autant plus forte qu'en 1994, les Sarajéviens sont au beau milieu du plus long siège de l'histoire du $\mathrm{XX}^{\mathrm{c}}$ siècle :

Ces dernières considérations pourront sembler outrées. Du point de vue qui est le mien dans cet essai, je les crois pourtant justes, profondément justes. La différence peut bien être incommensurable entre un Pelletier et un Milosevic, mais le pouvoir réel qui manque au premier n'empêche pas que son procédé de "gauche »- l'emploi révolutionnaire du mensonge contre un ennemi - pour être moins cynique, parce que moins conscient, entretienne une parenté avec les méthodes 
du second. Et surtout soit porteur du même désastre pour la souveraineté du peuple au nom duquel cela se commet. (SR, p. 48-49)

En rapprochant le nationalisme de Pelletier de quelques-unes des pires exactions de la deuxième moitié du $20^{\mathrm{e}}$ siècle, Larose ne fait, à tout prendre, que revenir à la thèse défendue au cours des années 1960 par les principaux animateurs de Cité libre: le nationalisme est toujours un grand péril. Ce n'est d'ailleurs pas un hasard s'il évoque Pierre Trudeau, comme s'il fallait donner raison à Pelletier, qui liait l'auteur de $\mathrm{La}$ petite noirceur à certains «fédéralistes notoires 》 :

Pierre Trudeau, qui s'est beaucoup fourré le doigt dans l'œil au sujet du Québec, avait pourtant, avant de s'aveugler, eu le temps de voir clairement une chose essentielle : la nature profondément empreinte de ressentiment du nationalisme québécois - comme de tous les nationalismes où l'identité domine le projet national. (SR, p. 47-48)

L'hypertrophie des associations finit même par faire passer Pelletier du nationalisme postcommuniste au national-socialisme. Ainsi, l'idée de posture présentée par Pelletier pour attaquer Larose « est ignoble et dangereuse, une négation de la vie intellectuelle, un critère d'infamie politique infailliblement faux et qui remplirait bien des camps si les maitres Jacques pouvaient tourner kapos.» (SR, p. 52) Larose ajoute : " Je ne dis pas que notre Pelletier soit stalinien. Il lui manque pour cela une certaine énergie systématique, une vraie dureté à laquelle, en dépit de tous ses efforts, il n'arrive pas : c'est qu'il se croit bon. » (SR, p. 52-53) Passant du nazisme au stalinisme sans coup férir, Larose écrase son argumentation. Il l'alourdit par des références hyperboliques sur la gauche et la droite qui finissent par étourdir plutôt qu'éclairer. Peut-on encore jouer? 
L'auteur de La souveraineté rampante succombe en quelque sorte au danger de l'ironie, qui se crispe en un sourire sardonique. Jacques Pelletier, de son côté, revendique une position faussement objective, aussi intenable qu'attaquable. Le pamphlet, par la violence de ses moyens rhétoriques, révèle et accentue la distance entre deux conceptions de la culture et du monde : l'une est romanesque, ironique, tandis que la seconde se veut concrète et sérieuse. Du même coup, en en montrant les limites et les vélléités déçues (le non-sérieux se braque, exagère, se fige ; le sérieux croit bêtement à l'objectivité des faits et du concret), le pamphlet les ramène, paradoxalement, dos à dos. Nous ne sommes peut-être pas sortis de la situation que déplorait Hubert Aquin, en 1962: «Un dialogue de sourds s'est ainsi établi au Canada français entre des penseurs qui, en réduisant leurs interlocuteurs à des produits conditionnés, nous enlèvent du même coup tout espoir en ce qui concerne leur propre puissance d'intellection ${ }^{54}$.»

\section{NOTES}

'Je remercie le Conseil de recherches en sciences humaines du Canada pour son soutien financier.

2 Jacques Pelletier, Les habits neufs de la droite culturelle. Les conservateurs et la nostalgie de la culture d'ancien régime, Montréal, VLB éditeur, 1994. (Coll. « Parti pris actuels »), p. 11. Désormais $H N$.

${ }^{3}$ Stéphane Baillargeon, « La guerre des clans », Le Devoir, samedi 5 mars 1994, p. D1.

${ }^{4} J a c q u e s$ Pelletier, Situation de lintellectuel critique. La legon de Broch, Montréal, XYZ, 1997, p. 69. (Coll. « Documents »).

${ }^{5}$ Gilles Marcotte, «Jacques Godbout, réformiste à vie », Le Devoir, samedi 30 avril 1994, p. D4.

"François Ricard, dans Baillargeon, «La guerre des clans », p. D1.

${ }^{7}$ Idem, « Le grand humour », l'Inconvénient, n" 5, mai 2001, p. 15-27. 
${ }^{8}$ Jean Larose, La souveraineté rampante, Montréal, Éditions du Boréal, 1994. Désormais $S R$.

"Pelletier, Situation de l'intellectuel critique, p. 72.

${ }^{10}$ Voir Yvan Lamonde, Historien et citoyen. Navigations au long cours, Montréal, Fides, 2008, annexe I.

"Pelletier, Situation de lintellectuel critique, p. 137. Ces propos remontent à 1976.

${ }^{12} \mathrm{Si}$, comme le dit Xavier Gélinas dans son histoire de la droite intellectuelle au Québec, le nationalisme est « un engagement compatible tant à la gauche qu’à la droite », un «iceberg [qui] vogue selon les courants et les impacts rencontrés ", il existe quand même certains traits qui le placent d'abord à droite : « Il est indéniable que des éléments de la sensibilité de droite la prédisposent au nationalisme, en tant que preuve d'une continuité historique et contrepoids à l'individualisme excessif et à l'abstraction universaliste d'une gauche jugée sans mémoire, sans racines. »Xavier Gélinas, La droite intellectuelle québécoise et la Révolution tranquille, Québec, Presses de l'Université Laval, 2007, p. 26.

${ }^{13}$ François Ricard dans Baillargeon, «La guerre des clans », p. D1.

${ }^{14}$ «On peut constater que les blocages de la discussion les mieux attestés dans la vie publique et ceux dont la raison ou la cause est la plus facile à localiser, ne tiennent pas à des raisonnements mais à des concepts, au recours à des concepts qui paraissent acquis et indispensables à l'un et fallacieux et scandaleux à l'autre. » Marc Angenot, Dialogues de sourds : doxa et coupures cognitives, Montréal, Marc Angenot, 2001, p. 39. (Coll. « Discours social/Social Discourse »).

${ }^{15}$ Alain Finkielkraut, La défaite de la pensée, Paris, Gallimard, 1987, p. 14.

${ }^{16}$ Fernand Dumont, « De quelques obstacles à la prise de conscience chez les Canadiens français ", Cité libre, n" 19, janvier 1958, p. 23.

${ }^{17}$ Jacques Godbout dans Marcotte, «Jacques Godbout, réformiste à vie », p. D4.

${ }^{18}$ Voir, à ce propos, Annette Hayward, La querelle du régionalisme au Québec (1904-1931). Vers l'autonomisation de la littérature québécoise, Ottawa, Le Nordir, 2006, $621 \mathrm{p}$.

1" "Un "je" nouveau, un "nous" culturel inédit, qui rejoint un "nous" humain, universel, international. La convergence de ces préoccupations, durant les années trente, est frappante, décisive pour la culture de l'époque ; cette 
question du particulier (nationalisme) et de l'universel (internationalisme) refera surface en 1950, dans Cité libre, et s'y révélera la pierre d'achoppement entre les "fédéralistes" et les "néo-nationalistes" qui argumenteront qu'on n'accède pas à l'universel par abstraction. " Yvan Lamonde, « La modernité au Québec : pour une histoire des brèches (1895-1950) », dans Yvan Lamonde et Esther Trépanier, dir., L'avènement de la modernité culturelle an Québec, Québec, Institut québécois de recherche sur la culture, 1986, p. 306.

${ }^{20} \mathrm{M}^{\mathrm{gr}}$ Félix-Antoine Savard, «Dissidence », Cité libre, n” 10, octobre 1954, p. 38.

${ }^{21}$ Jean Larose, La petite noirceur, Montréal, Boréal, 1987, p. 31.

${ }_{22}$ Pierre Vadeboncoeur, «La revanche des cerveaux » dans Une tradition d'emportement. Écrits (1945-1965), choix de textes et présentations par Yvan Lamonde et Jonathan Livernois, Québec, Presses de l'Université Laval, 2007, p. 129. Paru initialement dans Cité libre, n" 37, mai 1961.

${ }^{23}$ Jacques Godbout, dans Marcotte, «Jacques Godbout, réformiste à vie », p. D4.

${ }^{24}$ Voir, à propos de la dialectique de l'enracinement et du déracinement, les idées d'Yvon Rivard exprimées dans Christian Desmeules, "Que faire du mythe Aquin ? ", Le Devoir, 10-11 mars 2007, p. F3.

${ }^{25}$ Expression de Pierre Milot, Pourquoi je n'ecris pas d'essais postmodernes, Montréal, Liber, 1994, p. 7.

26 Jacques Pelletier, « Le Québec en culture », Le Devoir, samedi 16 avril 1994, p. A11.

${ }^{27}$ Ibid.

${ }^{28}$ Ibid.

${ }^{20}$ François Dumont, «L'essai littéraire québécois des années quatre-vingt : la collection "Papiers collés" " Recherches sociographiques, vol. 33, n" 2, 1992, p. 330 .

${ }^{30}$ Ibid., p. 332.

${ }^{31}$ 174a (traduction Dumont). Fragment tiré de Jean-Paul Dumont (dir.), Les écoles présocratiques, Paris, Gallimard, 1991, p. 21. (Coll. « Folio essais »).

${ }^{32}$ Expression de Maurice Duplessis évoquée par Yvan Lamonde, « La spécificité des intellectuels des années cinquante au Québec », Bulletin d'histoire politique, vol. 3, n"1, 1994, p. 24. 
${ }^{33}$ Jules Michelet, Le Peuple, s. 1., Grands Écrivains, 1987, p. 114-116.

${ }^{34}$ Friedrich Nietzsche, L'Antéchrist, Paris, Flammarion, 1996 [1994], p. 124, \& 57. (Coll. «GF $)$.

${ }^{35}$ "La culture, mot et concept, est d'origine romaine. Le mot "culture" dérive de colere - cultiver, demeurer, prendre soin, entretenir, préserver - et renvoie primitivement au commerce de l'homme et de la nature, au sens de culture et d'entretien de la nature en vue de la rendre propre à l'habitation humaine. [...] Il semble que le premier à utiliser le mot pour les choses de l'esprit et de l'intelligence soit Cicéron. Il parle de excolore animum, de cultiver l'esprit, et de cultura animi au sens où nous parlons aujourd'hui encore d'un esprit cultivé, avec cette différence que nous avons oublié le contenu complètement métaphorique de cet usage. Car pour les Romains, le point essentiel fut toujours la connexion de la culture avec la nature ; culture signifiant originellement agriculture, laquelle était hautement considérée à Rome, au contraire des arts poétiques et de fabrication. » Hannah Arendt, La crise de la culture. Huit exercices de pensée politique, Paris, Gallimard, 1972 (pour la traduction française), p. 271. (Coll. « folio essais »).

${ }^{36}$ Julien Benda, La trahison des clerss, Paris, Grasset et Fasquelle, 1975 [1927], p. 213-214.

${ }^{37}$ Ibid., p. 200.

${ }^{38}$ " [...] en ce moment, le livre, c'est Bourdieu et son tranche-baloney institutionnel ; imagine-toi donc qu'un zozo bourdieusard [Pierre Milot] m'a reproché de n'avoir pas tenu compte, daṇs mon analyse de la modernité littéraire québécoise, des "relations objectives entre les agents", et crois-moi, il était sérieux ». Larose, La petite noirceur, p. 194.

3) Pelletier, Situation de l'intellectuel critique, p. 67-74.

4' Milot, Pourquoi je n'écris pas d'essais postmodernes, p. 15.

${ }^{+1}$ Larose le dit bien dans La souveraineté rampante : « [Pelletier] omet de préciser que les phrases incriminées - par lesquelles il essaie de me faire passer pour antiféministe et homophobe, - effectivement imprimées "en français dans le texte" à l'endroit indiqué, font partie, dans un dialogue, du discours d'un personnage qui est une vraie caricature. » (SR, p. 49) La lecture du dialogue révèle en effet que le personnage, sorte de génie fou qui cherche à faire un " doctoral total », est caricatural au possible.

${ }^{42}$ Larose écrit en effet : «Le programme démocratique québécois a pu procéder d'une vision généreuse. En réalité, il n'a accompli que la partie la plus facile 
et la moins réfléchie du projet : empêcher que la culture humaniste ne soit réservée à une élite restreinte de privilégiés, comme c'était le cas au temps du cours classique. " Jean Larose, L'amour du pauvre, Montréal, Éditions du Boréal, 1998 [1991], p. 42. (Coll. «Boréal compact »).

${ }^{43}$ Je cite encore L'amour du pauvre: «Mais d'abord, il faudrait apprendre à reconnaître l'étrangeté de notre propre littérature. Quelque chose d'irréductiblement étranger donne aussi sa qualité littéraire aux cuvres qui ont été écrites chez nous. Au lieu de les lire seulement pour y vérifier ce que nous sommes, recherchons ce qui nous fait violence en elles, et demandonsleur une marque, une forme, une distance, une distance à traverser, une énigme à retourner. »Ibid.

${ }^{44}$ François Dumont résume ainsi ce qui distingue les revues l'Inconvénient, héritière directe de l'esprit de Liberté des années 1980, et Contre-jour : « Ce sont à la limite deux genres qui s'affrontent : l'ironie du roman et la croyance de la poésie, dans les deux cas au moyen de l'essai, qui reste la parole littéraire par excellence des membres des comités de rédaction. » François Dumont, « Un nouveau conflit de références. Trois revues littéraires québécoises contemporaines : Liberté, l'Inconvénient et Contre-jour", Cahier de l'Association internationale des études françaises, $\mathrm{n}^{\circ}$ 58, mai 2006, p. 196-197.

${ }^{45}$ De 1980 à 1986, François Ricard dirige la revue, alors que Jacques Godbout et Jean Larose sont membres du comité de rédaction. L'ironie y est à l'honneur : on notera, par exemple, cette parodie délirante du Tour de la France par deux enfants (1877), qui devient Le Tour du Québec par deux enfants, roman d'éducation par Mme E. Bertil dans le numéro de février 1986, et le célèbre numéro de février 1983, recueil de pastiches d'écrivains québécois intitulé "Nos écrivains par nous-mêmes ».

${ }^{4}$ François Ricard, La génération lyrique. Essai sur la vie et l'cuvre des premiers-nés du baby-boom, Montréal, Boréal, 1992, p. 10.

${ }^{47}$ Thomas Vauterin, dans une intéressante étude sur la méthode de la littérature dans La génération lyrique de François Ricard, en arrive à un constat semblable : « cette dévalorisation des froides vérités énoncées à partir du logos des sciences humaines par rapport à une chaude vérité littéraire existentielle peut aussi se rattacher à un courant plus large de contestation de celles-ci. Dans la constellation de Liberté, on connait le sort que Jean Larose réserve aux sciences de l'éducation ou à la sociologie qualifiée de bourdieusarde tout comme on peut nettement percevoir cette tendance chez Alain Finkielkraut [dans $L a$ défaite de la pensée]. » Thomas Vauterin, « Méthodes de la littérature dans La génération lyrique », Études littéraires, vol. 37, n"1, automne 2005, p. 85. 
${ }^{48}$ Larose, L'amour du pauvre, p. 206.

4) François Ricard, « Sur une idée de Léon Gérin ou de la littérature comme frivolité », Études françaises, vol. 27, n 3, hiver 1991, p. 89.

${ }^{50} I d e m$, « Le grand humour », p. 23.

${ }^{51}$ Pelletier, Situation de l'intellectuel critique, p. 72. Je souligne.

52 Vladimir Jankélévitch, L'Ironie, Paris, Flammarion, 1964, p. 122. (Coll. "Champs").

${ }^{53}$ « Il faut aussi comprendre l'idée de fiction, je dirais disposer d'assez de jeu souverain pour sentir la fiction, savoir suspendre la décision du sens le temps d'un jeu, ou d'un essai littéraire. » (SR, p. 56-57)

${ }^{54}$ Hubert Aquin, «La fatigue culturelle du Canada français » dans Mélanges littéraires II. Comprendre dangereusement, édition critique par Jacinthe Martel avec la collaboration de Claude Lamy, Montréal, Bibliothèque québécoise, 1995, p. 66. Paru initialement dans Liberté, no 23, mai 1962, p. 299-325. 